\title{
Rewriting Teacher Education: Food, Love, and Community
}

\author{
Imandeep K. Grewal* \\ Amanda Maher \\ Hanna Watters \\ Donacal Clemens \\ Kaitlyn Webb \\ Eastern Michigan University \\ *Corresponding Author: igrewal@emich.edu \\ Received : 2019-08-01 \\ Revision : 2019-11-15 \\ Accepted : 2019-11-22
}

How to cite this paper: Grewal, I. K., Maher, A., Watters, H., Clemens, D., \& Webb, K. (2019). Rewriting teacher education: Food, love, and community. Journal of Culture and Values in Education, 2(3),44-60.

\section{Abstract}

In this article, we present the intertwining stories of a teacher education learning community that is (re)writing the current dehumanizing narrative of standardization, crisis mongering, and the survival-of-the-fittest ethos that continue to harm our learners, teachers, and communities. We argue that when teacher education candidates are repositioned from consumers of theory and methods to inquirers of practice, their collectively constructed knowledge not only illuminates locally significant issues but also disrupts institutional hierarchies. Drawing from narrative inquiry theory and a collaborative methodical approach, we-a teacher education lecturer and students - share our personal stories of learning together in a required teacher education course and practicum placement at a local high school. Bringing together conceptions of voice, human capability, and "place," we provide a layered framework to understand pedagogical practices that operate to unravel systems of standardization and hyper-individualism. Our inquiry approach, public narration, and our democratization of knowledge serve as an example of teacher education pedagogy with a disruptive agenda.

Keywords: Narrative Inquiry, voice, teacher education, humanizing education

\section{Introduction}

Joyful. Loving. Nurturing. When one thinks about the United States public school system, these are not the affective qualities that come to mind. Rather, policy makers, corporate reformers, and the media wield marshalled statistics and inundate the public with messages of failure, crisis, and decline. These voices warn that the nation is losing its competitive edge on the global front, and their dominant narrative alludes to ambiguous enemies and advances metaphors of warfare. Educational reformers justify their subsequent agendas by preying on these manufactured fears, demonizing schools and encouraging a narrow-minded focus on individual survival. A person's viability equates to their presumed economic competitiveness and is 
measured by the quantification of their knowledge. It is a race (The American Recovery and Reinvestment Act, 2009) where only those deemed the fittest will survive. Written out of this narrative are compassion, justice, and interconnected identities, and ultimately, standardization regimes are a war against our humanity. We have come to believe that teacher education programs that adopt a human capabilities approach are grounded in place, value voice, and can serve as spaces of cultural transformation and counter-hegemonic disruption.

\section{Reclaiming Our Humanity}

Our purpose for our inquiry projects stems from the belief that stories of lived experiences when shared and honored alongside others-have the power to shift narratives (Clandinin, 2013). In order to rewrite the causes harmed by standardization, we share our own stories.

Iman begins her narrative:

"As a product of the traditional educational system, I had completely 'bought' into the purpose and process of teaching. The purpose: give students a 'good' education so they can get into a 'good' college which will get them a 'good' job allowing them to live a 'good' life. 'Good' in this context is implicitly assumed to be a measure of wealth. The process: 'teach' clearly defined, standardized, sequential series of facts/skills in silos of distinct subject areas and 'objectively measure' student achievement in each subject area.

"The first day of class each semester during the first decade of my teaching in a teacher preparation program were relatively fixed, almost prescriptive: syllabus; attendance; introductions; questions and answers. A significant portion of the first day of meeting the new group of students was spent pouring over the course expectations: required textbooks; list of assignments-how many points for each, was there a rubric to lay out a clear path to earning an A; attendance policy; and due dates. Term after term, the first day, much like the term itself, had a linear predictability. We, the students and I, were engaged in the serious work of 'teaching and learning.' My job was to ensure that I 'delivered' the entire expanse of content and 'objectively measured' student learning through assignments and tests. The students' job was to follow the schedule, be attentive during lectures, complete tasks by the due date, and accept the grade they received as a valid determinant of their ability to become teachers. This routine remained relatively fixed irrespective of the uniqueness of each new group in the classroom and the changing world outside the classroom."

Iman, an experienced educator and university instructor, shares a story that illustrates what Giroux (2015) called "a pedagogy of repression," defined as pedagogy that "kills the imagination, sanctions a deadening mode of memorization, and instills in students that discipline necessary for them to accommodate willingly to existing power relations at the expense of developing their capacity to be critical and engaged agents" (p. xii). Most of us are causalities of this pedagogy, but we know no other way. As a result, many educators adopt teaching practices that continue the cycle of repression and curtail voice. When educators fail to provide conditions that value voice, they deny students their humanity (Couldry, 2010). 
One day, Iman had a moment of clarity. She recalls:

"I don't know if this has ever happened to you. I began my class as I have done more times than I care to count, but a minute into class everything changed. It was as if for all these years I had been teaching with my eyes closed and now I had opened my eyes. Seemingly out of nowhere I had an 'aha' moment. It was as if all the pieces of the puzzle fell into place and I could see the picture in its entirety. While the students and I shared stories and laughter, but as soon as I took my position at the front of the room there was a significant shift in dynamics. I saw the students' retreat into themselves, their faces turning blank. It is in these moments that I realized that while I had taken great care to build some kind of connectedness with my students, I had not extended it to my teaching. I had never really taught in a way that challenged reproductive, hierarchical forms of pedagogy. A new chapter in my life began."

Because teacher-student roles are reinforced across instructional and institutional settings, resisting these hierarchal structures and their ideological underpinnings is challenging work. Pedagogy grounded in place challenges notions of these fixed roles across schools and communities, and begins with the cultivation of belonging (Lowenstein, Grewal, Erkaeva, Nielson, \& Voelker, 2018). It is from a sense of belonging that students can flourish and develop their capabilities as humans - of what they can do and what they can be (Walker, 2005). Reclaiming humanity also involves cultivating social resources that value and support voice. According to Couldry (2010), voice is a socially grounded, reflexive process that affords an individual the ability "to give an account of the world in which they act" (p. 91). This is not form of individualism; rather, it involves "exchanging narratives back and forth between our past and present selves, and between us and others" (p. 8). Bringing together conceptions of voice, human capability, and place, we provide a layered framework to understand pedagogical practices that operate to unravel the harms of standardization (see Figure 1).

It is accepted practice that scholarly studies begin with a research question and a defense grounded in formal knowledge, but inquiry grounded in the narrative process, argued Clandinin (2013), is justified in the context of lived experiences and is inspired by personal puzzles. By framing our work with our own personal struggles, institutional tensions, and wonderings, we recognize that we are challenging dominant research expectations and disrupting the hierarchizing of knowledge. Rejecting conventional research methods that seek to discover themes, answers, and underlying social patterns, we assert that our inquiry project is as much about our being and becoming as it is about the applications of a place-based informed teacher education course. By adopting a narrative design, we engage in the "story phenomenon" of living, telling, retelling and reliving (p. 34). In the writing of our stories-our life histories in context-we interrupt the roles that have been ascribed to us, and our stories become an expression of selfhood (Goodson, 2013). In this process of re-storying ourselves, Clandinin (2013) added, there is the potential to challenge institutional, social, and cultural narratives that limit our voice and narrow the possibilities of qualitative transformation. 
Our narrative method is grounded in the construct of inquiry as stance (Cochran-Smith \& Lytle, 1999). We adopt this lens and positionality towards our teaching and inquiry because it challenges problematic perspectives that view knowledge generation as discrete from knowledge as practice, a division that creates a hierarchy of knowers, thinkers, and doers. As research-practitioners, we embrace Cochran-Smith and Lytle's assertion that "knowledge making" is a "pedagogic act-constructed in the context of use, intimately connected to the knower" (p. 272). A primary purpose behind practitioner inquiry is the "democratization of knowledge," which Campano, Ghiso, and Sanchez (2013) assert begins with the principle that those in a context are in a position to examine themselves in that context. This stand is contextually meaningful, and Campano et al.'s own practitioner-researcher inquiry project demonstrated the emancipatory impact on their students. While knowledge is constructed collectively, this transformative potential reaches beyond the local. Narratives of knowledgemaking inform the theorizing of practice while also connecting to the work of other educators and communities of inquiry (Cochran-Smith \& Lytle, 1999). Our methodological approach is deeply personal, but we make our stories public with the aim that they will intertwine with other stories across time and space and amplify a shared sense of mutual agency.

Figure 1. A chart of humanizing pedagogical shifts that challenge methods of standardization.

Methodologies: The Process of Learning and Becoming with Others

\begin{tabular}{|c|c|}
\hline Standardization & Humanness \\
\hline Uniformity/Standardized & Uniqueness/Diversity \\
\hline Fixed & Constantly adapting/evolving \\
\hline Hyper-individualistic & Community/collective \\
\hline Predictable & Highly variable \\
\hline Controllable & Encourages open-mindedness \\
\hline Quantifiable & $\begin{array}{l}\text { Defies reduction to numbers; best expressed } \\
\text { through stories }\end{array}$ \\
\hline Focused on skills and content knowledge & Grounded in relationships \\
\hline $\begin{array}{l}\text { Relies on segregation: } \\
\text { of subject areas from each other } \\
\text { of emotions from intellect } \\
\text { of school from community } \\
\text { of learning from living } \\
\text { of nature from learning }\end{array}$ & $\begin{array}{l}\text { Expressed in interconnectedness of learning, living, } \\
\text { and feeling }\end{array}$ \\
\hline Learning and teaching are separate processes. & $\begin{array}{l}\text { Teaching and learning are part of the same } \\
\text { developmental and ongoing process. }\end{array}$ \\
\hline $\begin{array}{l}\text { Intelligence and capability are well defined and } \\
\text { students fall on a spectrum. }\end{array}$ & All students are uniquely intelligent and capable \\
\hline Passive & Empowered \\
\hline Focused on creating inequality and division & Prioritizes equality and dignity \\
\hline Hierarchical & Democratic \\
\hline Competitive & Collaborative \\
\hline Values compliance and silence & Expressed in dialogue \\
\hline
\end{tabular}


Grewal, I. K., Maher, A., Watters, H., Clemens, D., \& Webb, K. (2019). Rewriting Teacher Education: Food, Love, and Community

\section{Roles and Positionalities}

Collectively, we identify as a community of inquiry. One member of our community is the university instructor of a required social foundations course for all students aspiring for teaching certification, and three other research practitioners were students enrolled in that course. Another author is a doctoral candidate and methods lecturer in the teacher education department who has ties to the department's newly developed place-based teacher education program, NEXT. We formally came together in the fall of 2018, but our inquiry has no definite bookends. In addition, our classroom and methodological practices were not bound by space, activity, or time, and both the course and the inquiry project organically evolved as our individual and collective puzzles emerged. With no real starting point, narrative inquiry begins when the researcher comes "alongside the participant" (Clandinin, 2013, p. 34). While more equalitarian than other traditional research modes of inquiry, it still assumes a researcherparticipant relationship where the participant is an anonymous object of study. By adopting an inquiry-as-stance position, we reject the novice-expert distinction that splinters the democratizing of knowledge (Cochran-Smith \& Lytle, 1999), and for our inquiry project, we identified as a learning community who came alongside one another. More concerned with human flourishing than conformity, we did not name a primary investigator; we positioned ourselves as co-researcher practitioners and named the teacher education students as authors. Our narrative is a tapestry of our individual voices.

\section{The Setting: A Living Classroom}

"Flipping the focus from standardization and academic achievement to nurturing and supporting the humanness of students felt like a necessary disruption after my 'aha moment.' The first day of class post-awakening still includes an attendance and syllabus but with significant repurposing. The priority, on the first day and throughout the semester, is to create spaces and experiences shaped by humanness. This means a syllabus that has clearly stated outcomes while also allowing each unique group to determine their unique path; it means coconstruction of projects and papers; it means getting out of the classroom; it means replacing lecture with dialogue and experiences; it means individualizing assessment and goals; it means focusing on creating meaningful growth; it means being flexible and adapting throughout the term; and most importantly, it means placing love and community in the center of my teaching and learning."

Iman began the semester with more puzzles than answers, but she was committed to humanizing her classroom. Rather than having a list of prescribed activities, the course evolved as Iman carefully guided students through the necessary pedagogical shifts (Lowenstein et al., 2018) when connection to place is the goal. Iman co-taught this class as part of a block course that included a curriculum course and a course on social foundations. Students completed the required 30 pre-service hours of the practicum course at the local high school. The school district has a very complex history after being forced to merge with a neighboring district. For many of the university students, who mostly identified as white, it was their first time in a predominately African American or "urban" school. Shortly after arriving at the school on the 
first visit, a fire drill forced everyone to leave the building. The exit was orderly and pre-service students mingled among high school students. Later, a university student mentioned, "This school is nothing like I thought it would be. It is clean and much nicer and the kids are happy." These short sentences triggered a series of reflections and dialogue, mostly around assumptions and deficit thinking. Students agreed that they had a lot to learn about not only the students but also their community. Collectively, the instructors and students imagined a summative project that involved students spending time in the community's neighborhoods.

The aim was for the university students to begin to understand-even in a limited way-the lived experiences of the high school students and have the opportunity to grasp how complex histories and current practices interact to shape the destinies of the high school students they worked with during their placements.

As the vision of the project began to gain momentum, Iman arranged for a local historian to take the class on a walking history tour of the city. He was intrigued by the project and offered to share his wisdom. He divided the school district into meaningful zones and educated the students about the unique history of each zone. Students self-selected into seven groups and each group chose the zone they would investigate. Another community member-an activist and art educator-was also invited to work with the students as they gave shape to this project. She suggested that students tell the story of their selected zone through photographs. The university students also arranged to share stories of their community project over a shared meal with high school students from the partnering practicum classrooms. Throughout the semester-long project, groups were given time in class to plan and reflect, and at the conclusion of the course, students publicly shared the stories of the different neighborhoods.

\section{A Tapestry of Voices}

Members of the learning community narrated their experiences of the course and the summative community project. Iman narrates:

"Shifting the purpose of my teaching was relatively smooth, shifting the process not so much. I am after all a product of the traditional educational system, only just becoming aware of how deeply socialized I am to conform, to be compliant, be silent, and in essence to reproduce a hierarchical, profit-driven system. For years, I had seen how few Black and Brown students were in my class term after term, and when they were in my class, I did notice how they sat on the periphery, often in isolation. I noticed how passive and checked out my students were. I noticed but did nothing. And then the fog started to lift, and I was determined to change. I was the starting point of this particular disruption." 


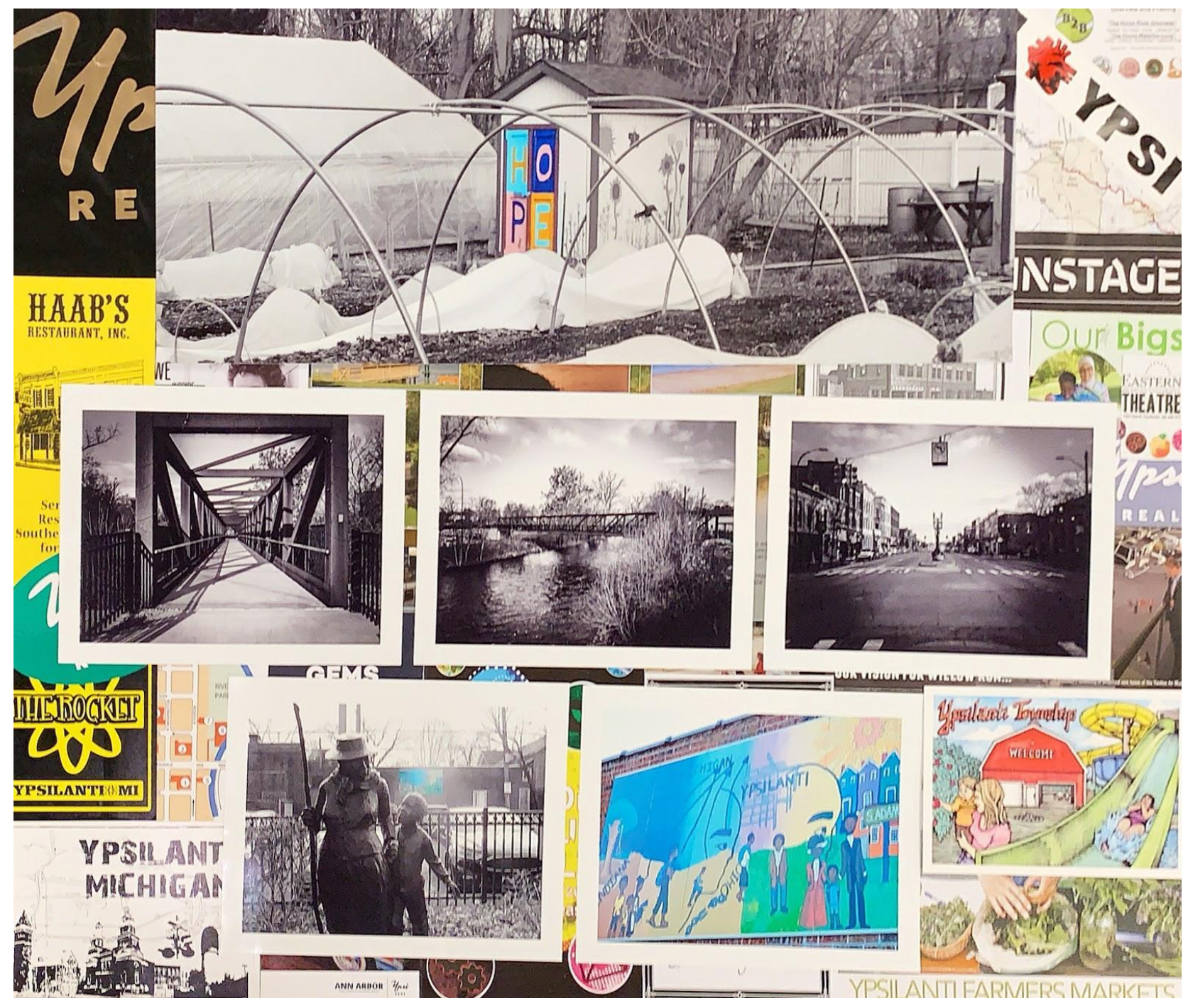

\section{This Space is Not Defined By Race}

Donacal is an aspiring secondary social studies teacher. He recounts:

"During the first week of class, we participated in multiple icebreakers that allowed the group to get to know each other in a non-traditional way. We also established group norms and classroom expectations to guide the curriculum in a way that was relevant to everyone in our community. These norms and expectations were not created to be the basis of group development, but rather reference points to help form interactions between students. From day one, it was never a dull moment in class, and there was always food-even for vegans like me. Food became a ritual that aligned with our needs, and having these needs met every morning was refreshing and energizing. 
"As we moved though the semester, the course began to revolve around our summative project. The name of the project had actually been changed quite frequently throughout the semester, and it was still seen as one of the most confusing projects that we were assigned all year. This was true, well at least until it was finalized, and I saw its purpose. The photo voice project has to be one of the most engaging and inclusive class group projects that I have ever participated in during my time here at EMU. Building that sense of community within the classroom prior to introducing the project was instrumental in making this shared experience inclusive. Although this may seem impossible with me being the token black male in the class at the time, my peers' level of cultural competency helped me feel comfortable in classroom sessions throughout the semester. This culture of care within our learning community became so strong that almost every student felt empowered and encouraged enough to participate in class discussions.

"What had become ingrained in our weekly sessions closely resembled that of what we read in class about 'humanness.' This concept was manifested in many ways as the class went on. One of the most valuable forms it took was that of emotional vulnerability. Being able to share tears, laughs, smiles, and frowns without thinking twice is what I believe ultimately connected us in a way that we will never forget. Just the thought of college students going their entire semester without knowing the name of the person they sit next to has now become weird to me. Who knew that a non-traditional classroom setting would impact us socially and emotionally? I know for a fact that I hadn't a clue. This was obviously something that the majority of us had experienced for the first time. However, this would not be the last time my fellow classmates and me would have the opportunity to connect on this level either.

"This course highlighted how excluded I felt in my other courses. It's not taboo for someone like me to be the only black student within most classes in my field, but the thought of my exclusion being predetermined is what bothers me the most. This absence of belonging and cultural competency in these traditional classrooms is mentally draining for someone like me and does nothing to promote the inclusion of all students' perspectives/experiences. In most cases I am invisible and can easily be overlooked by professors and students alike. During my sophomore year, I had the courage to ask my professor about his views on the upcoming presidential election, and then my professor used a slew of derogatory terms to describe and insult a man who I believed to be a prominent figure in the black community. Ben Carson was still running a 2016 presidential campaign, and my professor's response to him announcing his campaign was that 'he's out his cotton-picking mind.' This not only left me speechless, but it also had me looking around the classroom for confirmation of what I just heard and to see if anyone that represented the majority would speak up and say something. Nope, not a soul called the professor out, and instead awkward silence filled the room for a brief moment and it finally hit me that I was alone. I felt alone, disempowered and hopeless. After that display of exclusion, it was as if I was completely invisible."

Donacal's lived experiences capture the racialized contradictions of Black men in historically White institutions of higher education (Smith, Hung, \& Franklin, 2011). On one hand, African American males are promised a piece of the American dream if they go to college and work 
hard, but Donacal's experience is an example of a racialized microaggression that causes him to feel invisible and voiceless. Smith et al. (2011) argue that the regularity of microaggressions - "subtle verbal and nonverbal insults directed at People of Color" -across universities create climates that produce racial battle fatigue among Black men (p. 67). Donacal reflects this hopelessness, but Iman's course was different. It provided a space of healing and empowerment for Donacal. He adds:

“Another incident occurred while taking Iman's course when we were visiting our local high school. Upon arrival, a faculty member came into the class to speak with us about restorative practices and how it has helped increase students' overall performance in school. However, while speaking about the demographics of a predominately black school in relation to the racial occupation of Ypsilanti and Detroit, he used the phrase 'white flight.' Although I did not react immediately, it also made me wonder if the same terminology would have been used if our class had been predominantly black. I think not! I knew in this course, I had the power to take this up with Iman and the rest of the class, and the next day we got in a circle and discussed this issue and how it made me feel excluded. Instead of doing what was scheduled in the syllabus, we addressed an issue that I believed threatened our beloved community. Knowing that several students caught what was said as well and knew it was wrong was invigorating. Thus, having the support of my professor and fellow classmates felt empowering and helped me navigate through this injustice easily. In comparison to the incident explained earlier, this feeling of isolation was countered by community engagement. With that being said, after being excluded in spaces due to my race for so long, it felt amazing to finally be included in a learning community."

Figure 3. Document of student reflection.

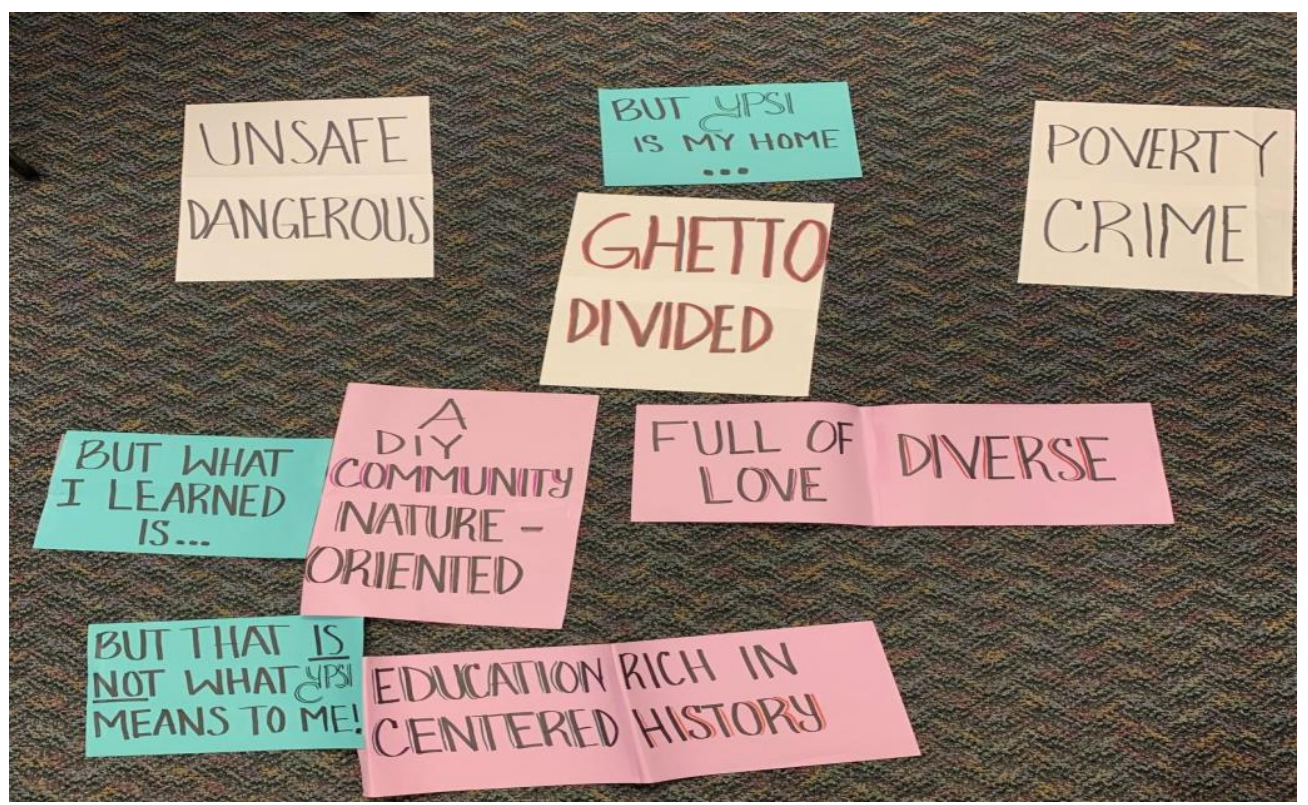




\section{Vulnerability in Education Does Not Equal Weakness}

Hanna is an aspiring secondary integrated science teacher. She reflects:

"Bravery is not something I often associated with learning. Theatre maybe, sports for sure, debate-I suppose, but the classroom is never a space I imagined could be for bravery. That was until I was asked to be brave. I hadn't yet experienced any form of relationship-building in college. I had met professors who would joke around with me and laugh, some who may remember my name, a few who I even still go to their office hours for help in other classes, but none like my EDPS 322 professor, Iman Grewal. She intentionally forged relationships with all her students so that they had someone they could rely on, someone they could come to, and someone they knew would support them through anything. This was something I saw on occasion with a few of my high school teachers, but never in college, nor to this extent of effort. It was such a change, going from the construct of an education system that was cold and distant to one that was warm and safe and open. A part of me didn't want to put in the effort because of the way I was conditioned, but it was so rewarding to become a part of such a community. Then, I became even more fortunate when I was enrolled in a block class with Iman and another instructor, Ethan Lowenstein.

"I didn't always know I wanted to be an educator. Like many adolescents, all I knew was that I wanted to help people. I quickly discovered that I wasn't able to adequately fulfill this want considering that I needed help myself. People who took one look at the cover of my story immediately drew conclusions about who I was as a person and my capability. A poor girl, with no family, nor any footsteps to follow in, many people saw me as incompetent. I thought I knew who I was and who I wanted to be, but I was not spared the ability to be easily impressionable and was convinced that everyone knew better than me. That there was nothing I could amount to that was of any value. That I was not only 'at risk' but that I myself was a risk. No use watering a flower that won't grow. I did grow, though. Time and time again of opening myself up, letting people see me as more that what I was preconceived to be, gave me the power to live a life that was worth pursuing."

Having experienced homelessness in her youth, Hanna's schools ascribed to her a position of "less than," and the weaponizing toll of deficit ideology-often used to blame and shame children living in poverty (Gorski, 2016) - eroded her feelings of self-worth and confidence. For Hanna, her teacher education course became a space of healing and courage. She adds:

"Iman not only gave me the courage to be brave, but they also offered me guidance, compassion, and the acknowledgement that I was valid and valued. The class was nothing like I had imagined an actual class could be. It was exactly the environment that set students up for success. The type of success that isn't measured by test scores or grades, but instead is reflected in effort, commitment, passion, and a level of intrinsic motivation that can only be found in worthwhile teachers. It became a space where I felt known, competent, and safe enough to be vulnerable and tell my story in a way that revealed parts of myself I never had before. These acts of personal exposure did not come without struggle. I contested the idea of 
being honest to someone about things I had been taught to feel ashamed of. The life I had grown up in did not allow for much imperfection, stemming from the shear societal fact that because I lived in poverty, I was already diseased with the flaws of a world lacking luxuries. Discussing the actuality of my life with no guarantee of comfort or empathy was a new type of terror I hadn't yet endured. The fear was pacified, though, by the respect and trust that had been composed by the kindness and understanding from the individuals I shared my experiences with. I had to be intentional with my bravery, considering how high stakes it is in our culture to show weakness. Vulnerability is often shunned, and those who display acts of vulnerability are commonly treated as outcasts. This new environment, though, grew to be a place that fostered humanity and love in a way I had never known, through the use of norms, conversation, facilitated prompts, and the nurturing of basic needs-like food and love.

"We began the first day of classes with community-building activities and the introduction of 'papers.' Iman and Ethan were adamant that we not call them 'assignments,' and they would not be graded by points. I recall there was one with a vastly long and intimidating title ending in 'community engagement.' I wasn't quite sure what it meant then, or the level in which it would change what the class would become. This project was intended to allow us prospect teachers to become a part of the community where the students whom we were observing belonged to. The underlying principle was that in order to teach students in a valuable and authentic way, you have to truly know your students, and one of the most effective ways to do that is by understanding the communities they belong to. I remember thinking that I was too much of a stranger to them that I wouldn't make a difference. That these students probably couldn't care less if a group of young adults, who were using their school as a checkpoint on their way to their careers, put in effort to become part of their world. I was wrong.

"The walk with the local historian was jarring to say the least. Our university, even though it is in Ypsilanti and very close to our placements, is very separate from the communities that belong there. Not many of us knew much about this area unless we grew up close by. A lot of us had our own personal biases and had formed judgements largely based on rumors about the city. Changing these notions began with first admitting that we had them and then replacing them with the truth. While walking with the historian, I was in awe of the amount of information that this one man had about a place I didn't know had so much history. I felt something for this city and its people, that made me want to learn more and more. Having this experience with the whole class gave us all something to bond over. I could feel us stitching together experiences and fabricating our own community. Simply being outside of the classroom didn't make learning feel so forced. It gave us an opportunity to be human and alive. I could say it really was a breath of fresh air. Upon returning and reflecting, it became obvious that I wasn't the only one who knew very little about this city. Everyone discovered a newfound interest in this project, even though there still wasn't a clear-cut design to what I was going to be.

"After sectioning off and separating into groups, we had a goal for our zone: to tell the story of our community. This goal in itself is so very different than any other type of learning I had done in any of my classes. 'Story?' 'Community?' These words were based in humanity, based in the experiences of other people, something that was not traditionally associated with the 
education system unless it was $9^{\text {th }}$ grade English class and the people you were learning about had no effect on your life. This project was real; the pain, struggle, strength, achievement, and power of these communities was real. We discovered this first hand in our section as we talked with business owners, community members, librarians, residents, etc. Everyone seemed so invested in the city and their role in it, that I could feel myself longing for the same type of community wherever I end up teaching. I realized the true value that relationships held to these people and the level of vulnerability you had to be willing to display in order to truly bond with individuals.

"Soon, the project became about telling these stories through pictures. It was a debate between what held truth and what was being told, between strength and deficit, between humanity and machinery. We wanted to fight for the truth of these communities because we as individuals knew what it was like for people to see you how they wanted to. We all experienced being told we were something we weren't, and we channeled that into this project. In order to go into these neighborhoods and view these areas with unbiased eyes, we had to not only face our own flaws but understand the labels that people put on these communities and how they have affected them. Finally, we had an opportunity to make amends for all the times we let ourselves feed into the rumors and gossip that flows from a society and culture that looks down on the telling of stories and the manifesting of uncomfortable places. We were able to start a chain reaction of stories and experiences about the real Ypsilanti communities and the assets they held. Together we discovered a community that fought for its members, that supported its students, that had a voice and used it to cling to values that were threatened to be taken from them. We found communities cemented in strength.

"When we were finally able to share the stories of Ypsilanti, we were taken aback by how much of a community we had become in the semester we had been together. We discovered the level of acknowledgement some of the students at the high school we were observing at felt, knowing that we put in this effort to understand them, their communities, and where they came from. Seeing others valuing them, gave them more reason to value themselves and to hold outsiders accountable for what they don't know. A lot of the things that I learned, I couldn't tell you the exact moment of learning them like I could in most classes. They were processes, they were meaningful, and these lessons are ingrained in me through experience. I had to be vulnerable, brave, reflective, open-minded, critical, and adaptive in order to achieve such success with this project." 
Figure 4. An example of the neighborhood storytelling project.

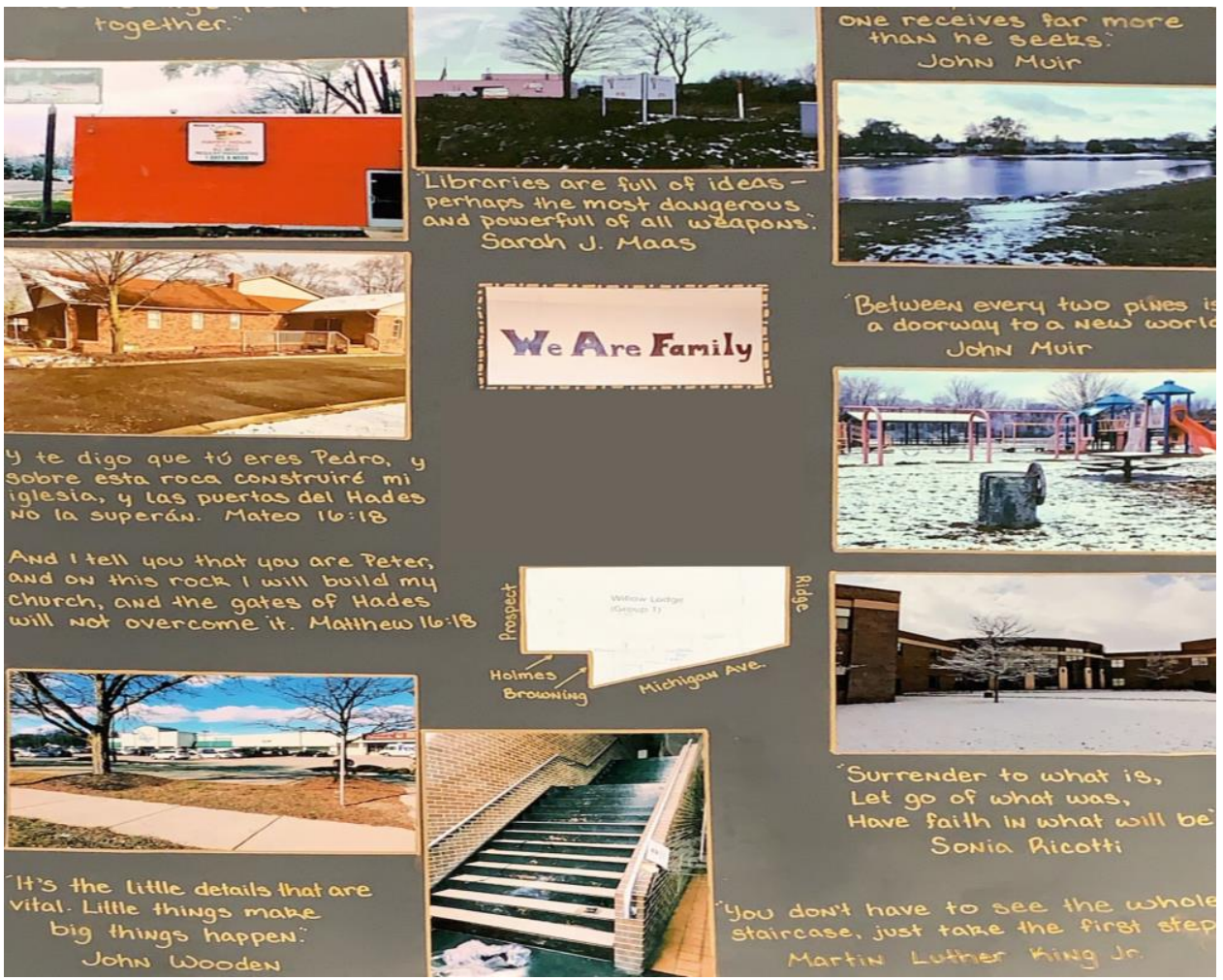

\section{The Deconstruction of a Traditional Classroom}

Katie is an aspiring secondary social studies teacher with a focus on history. She narrates:

"When one thinks of education, the common thought process usually involves a few things. A small classroom loaded with two dozen or so desks, bored students, and an overworked, very tired teacher standing at the front lecturing about this or that. All the while, either party is gaining nothing of apparent value. Sure, the information is arguably important and the knowledge that comes with it will ultimately do the students some good, especially for those who intend to continue through academia, but what about what's underneath? The people behind titles and the children behind the names you check off your attendance sheet: What about their humanity? Their thoughts? Their feelings? Well, when I first entered this learning environment and was given this question, I did not have an answer. In fact, all I had was an apprehensive approach from years and years of being taught that your 'feelings' were checked at the door whenever you entered a classroom.

"I will admit, I did resist. I rolled my eyes when I was told that we would be tasked with 'engaging in the community' and that this would be one of our major 'projects' for the semester. It left me thinking, 'this isn't my home, this isn't my community, why should I?' All I wanted was to get my grade and move on. No friends, no relationships, nothing, just get in and get out. But I learned almost immediately that this was not going to happen. On day one, Iman had us get into groups and asked us to do something. She asked us to share some of the key points in our 
life, 3 or 4 events that we thought made us, well, 'us.' In other words, she asked us to be vulnerable with strangers. This was a completely terrifying prospect; yet, I decided that maybe she was onto something so I went for it. I opened myself up to a handful of strangers and, in turn, opened myself up to something incredibly special.

"As our class continued, I found that this 'community engagement' was more than just your typical project. We were not only expected to go into the community and take a few pictures, we were expected to actually get to know it. It started with a local historian who helped to open my eyes to the tension between the community and the school I had lived at for the past four years but had not called home. It continued when, about halfway through the project, there was a realization that the project needed to change. Through dialogue, discussion, and a bit of vulnerability from both our professor and ourselves, we changed it. It became something more than just some vague 'get involved with the community' type of thing to a purpose of changing the narrative.

"After we were broken up into groups, we chose sections of the city and were sent to photograph places that added value to it. Thankfully, with the help of some of the local high school students, we were able to pinpoint the places that they deemed were important. Places like parks, restaurants, stores, and areas that they felt were the strengths of the city. Because of the nature of this project, this was not something that could be done in a day. This project spanned the course of several days of getting to know our little section of the community until we had enough to create some sort of display of all of our images and tell our story.

"For me, part of that story was about getting to know myself while getting to know the city. To further explain, I had never been very far off of campus until I was assigned this project. I believed the myths that I had been fed, myths that the city was dangerous and that the nicest part of it was the Eastern Michigan campus. But the more we explored, the more I found those assumptions to be wrong. There was a little library that turned out to be wonderfully rich in information, a local almost hole-in-the-wall restaurant had some of the best food I'd ever eaten, and the kids that I thought could not have cared less about us did care because we cared about them first and listened to stories about their experiences and lives in their community."

As Katie discovers, community engagement and storytelling is more about self-reflection than it is about the learning about the "other." Deconstruction of our worldviews and system of binaries are critical to community and collective empowerment (Westboy \& Dowling, 2010), and as Katie crosses physical and socially-manufactured boundaries, she recognizes that her constructed notions of rich/poor and college campus/urban community are limiting and harmful to our collective power. She comes to realize that by understanding "them," she came to understand herself, and she recounts her revelation:

"To put it plainly, I found out that I was wrong. Everything I thought I knew about Ypsilanti, everything I thought I knew about the way a class could be conducted, and everything I thought I would take away from this class was wrong. But I found that I was grateful for it. I was grateful for the ability to be uncomfortable, to be vulnerable in a space where I should not have been 
able to do so. That vulnerability allowed me to make stronger connections with every single aspect of this project. This includes the people I had the pleasure to work with, all of whom are people I believe I will be friends with for years. If I have learned anything, it is that sometimes things have to break in order to grow back stronger. Whether this is a personal preconception, an ambitious but complex project, or a poster board you mistakenly trip over, sometimes things need to change in order to become what they are meant to be."

Figure 5. An example of the neighborhood storytelling project.

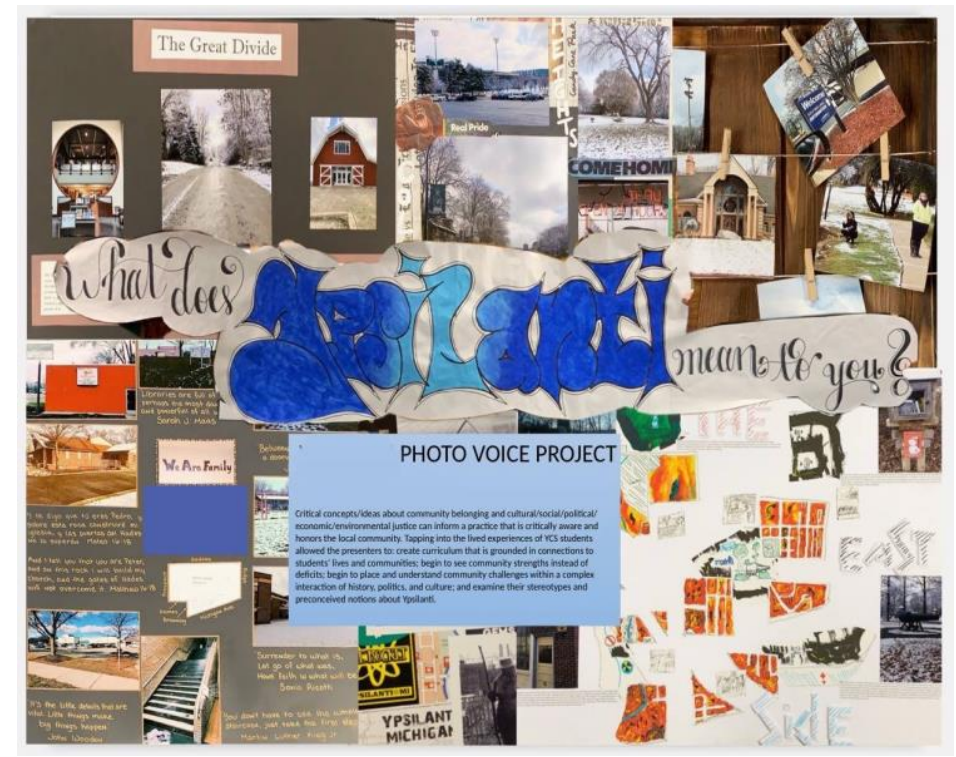

\section{Discussion}

Freire (1974) emphasized that transformative praxis begins with the stories of everyday life experiences, and our stories are grounded in a common theme-we were all wounded by school (Olson, 2009). Donacal described feeling "invisible," and Hanna said she felt that teachers often saw her as "incompetent" and "a risk." These are the wounds of numbness and underestimation, and Olson (2009) added that school wounds make students feel less courageous in their learning. We add that these wounds also make us less courageous in our teaching, and our healing journey - as university educators, scholars, and students -involved narrating, contextualizing, and understanding our wounds. Just like young learners, trusting relationships are imperative for adult learning and transformation (Drago-Severson, 2009), and by fostering a culture of trust, we became brave in our learning, courageous in our defiance of our internalized expectations, and empowered by our vulnerabilities. Our stories are more than a recounting of personal and collective healing; they are emblematic of a system that devalues diversity, creates deficit, and erodes human capabilities.

In addition to narrating our own journey of belonging and becoming, our stories also illustrate humanizing theory in action. An educator's political clarity regarding the success-failure methods of schooling are a significant precursor to pedagogical change (Bartolomè, 2009). 
Iman described her clarity as an "aha moment," and from there she made a transformative shift from "a narrow and mechanistic view of instruction to one that is broader in scope and takes into consideration the sociohistorical and political dimensions of education" (p. 340). Bartolomè (2009) argued that this shift is a necessary first step towards humanizing pedagogies that equalize power relations and cultivate democratizing spaces.

Rejecting one-size-fits-all notions of traditional methods and expected teacher-student roles, we embarked on pedagogies of place-making (Westboy \& Dowling, 2010). Community educators Westboy and Dowling proposed that this transformative approach begins at the microlevel and involves the nurturing of interpersonal relationships through dialogue. Identifying as a community of inquiry, we naturally began with dialogue. We also ate together, and the sharing of food became a loving act of communion. Food was an important element to our bonding process of place-making. At the mezzo level, place-making moves from personal relationships to purposeful action groups and involves going public with inquiries. There is no playbook or syllabus for banding, and as our negotiated neighborhood project organically grew, some students reported feelings that the journey was "confusing" and destabilizing. But Westboy and Dowling (2010) provided assurance that the "method in the madness" (p. 65) leads to clarity and the formation of stronger bonds across groups, and as we progressed in our storytelling, we formed bonds with high school students, community activists, and members of our neighborhoods. We also found clarity in banding with others, but neither our culminating sense of awareness nor the end of our semester mark the conclusion of our story. We continue to be focused on building sustainable partnerships and bridging with other teacher education initiatives and community organizations. By going public with the narration of our stories, we are deeply committed to the "profoundly humanizing process of co-creation" (p. 27).

\section{Conclusion}

Iman concludes:

"My disruptive journey has been slow, peppered with failure, cemented by bravery, wrapped in love, buoyed by laughter, nourished with food, protected by caring relationships, inspired by radical shifts in thinking, set back with self-doubt, motivated by clarity of purpose, and sustained by the growing empowerment and confident voices of my co-learners/my coteachers."

Joyful. Loving. Nurturing. Together, our evolving narratives reflect a transformative impulse emanating from within self and within the institution. As Hanna adds to the narrative, "Creating mutualism through vulnerability helped me feel authentic, human, and real. This is the first time I ever felt as though my story was worth telling." When teacher educators and aspiring teachers create learning communities that are grounded in "place" and value voice and the democratization of knowledge, they have the power to humanize classrooms and repair the wounds caused by the weapons of standardization. This is only the beginning of our story, and our learning and inquiry initiative is continuing to rewrite the narrative in our teacher education program, local schools, and communities. 


\section{References}

The American Recovery and Reinvestment Act of 2009, Pub. L. 111-5 (2009).

Bartolomè, L. I. (2009). Beyond the methods fetish: Towards a humanizing pedagogy. In A. Darder, M. P. Baltodano, \& R. D. Torres (Eds.), The critical pedagogy reader ( $2^{\text {nd }} \mathrm{ed}$.) (pp. 338-355). New York, NY: Routledge.

Campano, G., Ghiso, M. P., \& Sanchez, L. (2013). "Nobody knows the...amount of a person": Elementary students critiquing dehumanization through organic critical literacies. Research in the Teaching of English, 48(1), 98-125.

Clandinin, D. J. (2013). Engaging in narrative inquiry. Walnut Creek, CA: Left Coast Press.

Cochran-Smith, M., \& Lytle, S. (1999). Relationships of knowledge and practice: Teacher learning in communities. Review of Research in Education, 24, 249-305.

Couldry, N. (2010). Why voice matters: Culture, politics, and neoliberalism. Washington, DC: Sage.

Drago-Severson, E. (2009). Leading adult learning: Supporting adult learning in our schools. Thousand Oaks, CA: Corwin Publishing.

Freire, P. (1974/2014). Educating for critical consciousness. New York, NY: Bloomsbury.

Giroux, H. A. (2015). Education and the crisis of public values ( $2^{\text {nd }}$ ed.). New York, NY: Peter Lang. Goodson, I. F. (2013). Developing narrative theory. New York, NY: Routledge.

Lowenstein, E., Grewal, I. K., Erkaeva, N., Nielson, R., \& Voelker, L. (2018). Place-based-teacher education: A model whose time has come. Issues in Teacher Education, 27(2), 36-53.

Olson, K. (2009). Wounded by school: Recapturing the joy in learning and standing up to old school culture. New York, NY: Teachers College Press.

Smith, W. A., Hung, M., \& Franklin, J. D. (2011). Racial battle fatigue and the miseducation of Black men: Racial microagressions, societal problems, and environmental stress. The Journal of Negro Education, 80(1), pp. 63-82.

Walker, M. (2005). Amarya Sen's capability approach and education. Educational Action Research, 13(1), pp. 103-11

Westboy, P., \& Dowling, G. (2009). Dialogical community development: With depth, solidarity and hospitality. West End, Australia: Tefina Press. 